\title{
Nanoscale
}

CrossMark

\& click for updates

Cite this: Nanoscale, 2016, 8, 5387

\section{Correction: Dry shear aligning: a simple and versatile method to smooth and align the surfaces of carbon nanotube thin films}

D. D. Tune, ${ }^{\star a, b}$ B. W. Stolz, ${ }^{a}$ M. Pfohl ${ }^{a}$ and B. S. Flavel ${ }^{\star^{a}}$

DOI: $10.1039 / c 6 n r 90039 a$

www.rsc.org/nanoscale
Correction for 'Dry shear aligning: a simple and versatile method to smooth and align the surfaces of carbon nanotube thin films' by D. D. Tune et al., Nanoscale, 2016, DOI: 10.1039/c5nr08784h.

Fig. 3 in the published article should be replaced with the correct version shown below:

a)

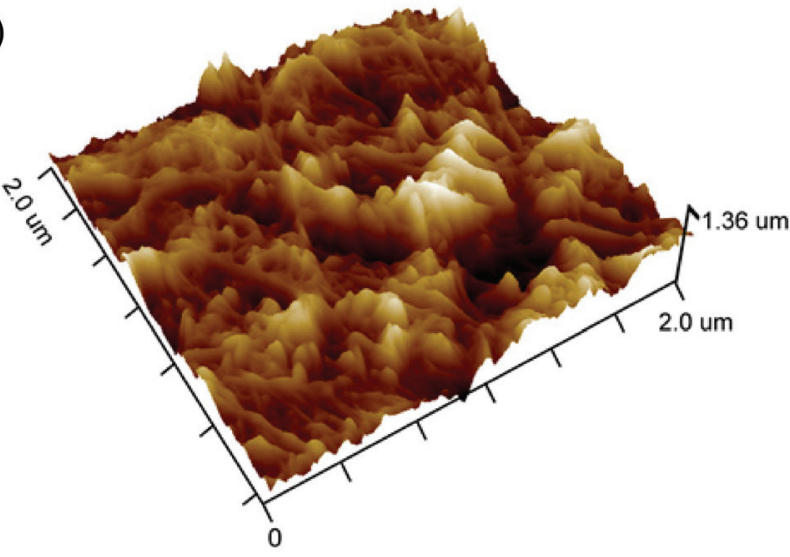

c)

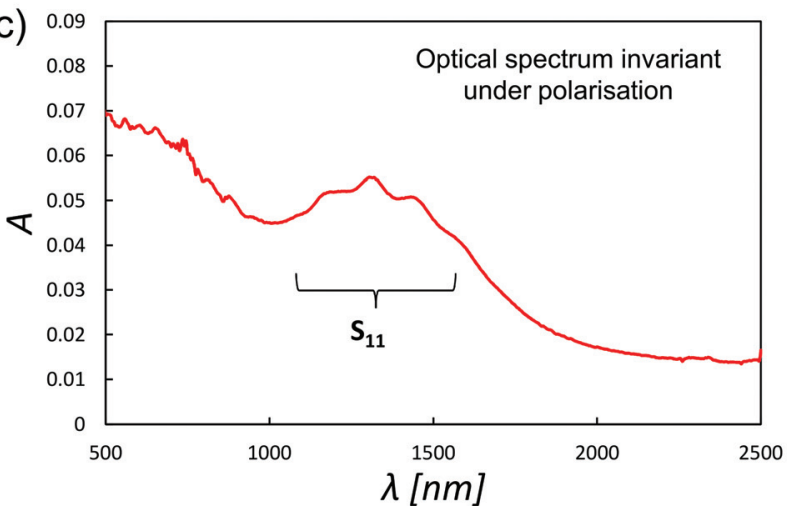

b)

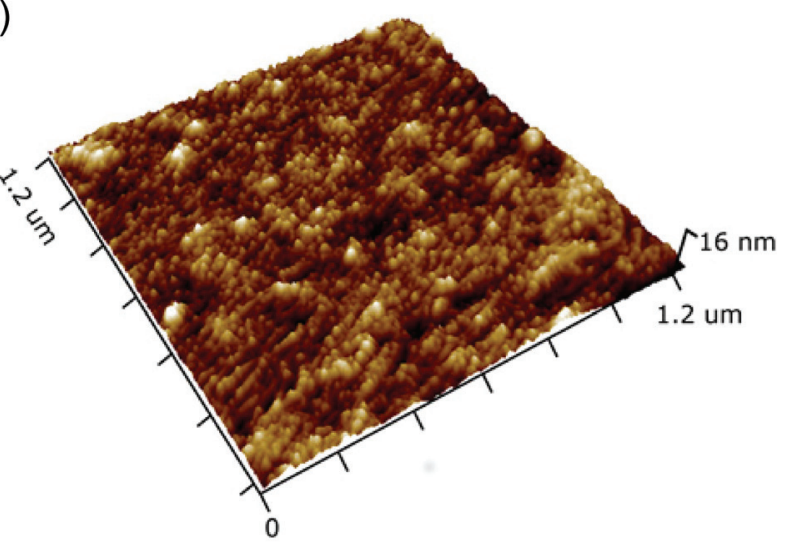

d)

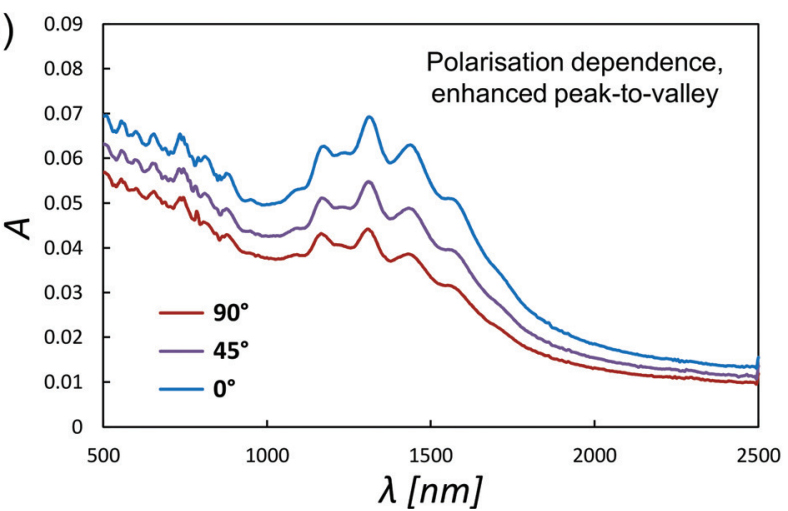

Fig. 3 (a) and (b) show 3D AFM images of a vacuum filtered nanotube film before and after DSA, respectively, while (c) and (d) show the corresponding polarised optical spectra.

The Royal Society of Chemistry apologises for these errors and any consequent inconvenience to authors and readers.

${ }^{a}$ Institute of Nanotechnology, Karlsruhe Institute of Technology, 76021 Karlsruhe, Germany.E-mail: daniel.tune@kit.edu, benjamin.flavel@kit.edu ${ }^{b}$ Centre for Nanoscale Science and Technology, Flinders University, Adelaide 5042, Australia 